\title{
The radial intercepts method for measuring bronchial mucous gland volume
}

\author{
A. F . A L L I \\ Department of Pathology, College of Medicine, University of Benin, Benin City, Nigeria
}

\begin{abstract}
Alli, A. F. (1975). Thorax, 30, 687-692 The radial intercepts method for measuring bronchial mucous gland volume. A new linear method, the radial intercepts method, has been introduced for quantitating the components of the bronchial wall. The method is an adaptation of Rosiwal's (1898) original linear measurement technique, but, unlike Rosiwal's, the radial intercepts method takes measurements along radii at regular sectoral intervals. The method is reproducible and, from its high correlation with the standard planimetric, cut-weigh, and point-count techniques for quantifying bronchial wall components (Bedrossian, Anderson, and Foraker, 1971), it is concluded that the method is reliable.
\end{abstract}

Reid (1960) measured the thickness of bronchial glands which lay between cartilage plates and the basement membrane, and also measured the wall thickness, which she defined as the distance between the basement membrane and the inner perichondrium, at the same site. She expressed the values as a ratio of gland thickness to wall thickness ( $\mathrm{G} / \mathrm{W}$ ratio). This is now known as the Reid Index.

Reid made only one or two such measurements per bronchial transection, but it was later shown (Restrepo and Heard 1963a, b; Thurlbeck and Angus, 1967) that since glands are normally present between cartilage plates and in the membranous and outer perichondrial tissues of the bronchi, measurements confined to sites where glands are present between cartilage plates and the basement membrane may not represent the true Reid Index for the case. Thurlbeck and Angus (1963, 1964) and Hayes (1969) made multiple measurements, but again only glands lying between cartilage plates and the basement membrane were used. Though multiple measurements improve the correlation slightly (personal observation), it has been shown (Bedrossian, Anderson, and Foraker, 1971) that differences still exist between the Reid Index determined only for the glands lying between cartilage plates and the basement membrane, and measurements which take account of all the glands in the bronchial transection.

Bedrossian et al. (1971) compared the methods for quantifying bronchial morphology, and in the process showed that the point-count method (Dunnill, Massarella, and Anderson, 1969) and the determination of gland area (cut-weigh method of Restrepo and Heard, 1963b) correlated highly with a standard planimetric area measurement of bronchial glands, bronchial wall, and connective tissue. On the other hand, as shown by these authors, the Reid Index correlated poorly. Bedrossian et al. (1971) gave the reason for the poor correlation of Reid Index with planimetric measurements as the fact that Reid's method (a unidimensional measurement) did not take account of all the glands in the bronchial wall, but planimetry, the point-count, and cutweigh methods, which are two-dimensional, did take account of all the glands and the whole of the wall.

The method described below is designed to show that linear measurements somewhat similar to that of Reid (1960) but differing from Reid's in that they are based on consistent cyclical sampling, can take account of the entire wall and all the glands in the bronchial wall, and can correlate well with cut-weigh, point-count or planimetric measurements. This new technique is called the radial intercepts method. It is an adaptation of Rosiwal's technique (1898) and, as explained by that author, is an area measure.

\section{ESTABLISHMENT OF THE NEW METHOD}

In order to establish the reliability of a new method, it must be shown to correlate highly with accepted standard methods. 
In the course of establishing the radial intercepts method as an accurate technique for determining bronchial gland volume, the cutweigh and the point-count methods were simultaneously carried out for comparison. It was justifiable to use only the cut-weigh and the point-count methods as controls in place of planimetry because these methods have been shown to be closely comparable to planimetry (Bedrossian et al., 1971). However, in one case planimetric measurements were carried out along with the other methods as a test case.

MATERIALS Fifty bronchial transections used in this experiment were obtained from 50 random necropsies which formed part of the 359 cases studied in Nigeria for the survey of the prevalence of chronic bronchitis and emphysema. A fresh bronchial ring 5 to $10 \mathrm{~mm}$ long was carefully dissected free of connective tissue. It was obtained at necropsy from the main bronchus about $25 \mathrm{~mm}$ below its origin at the carcina, and was fixed in buffered $10 \%$ formalin for at least 72 hours. Complete $5 \mu$ bronchial transections were cut and were stained with haematoxylin-eosin, Alcian blue, and periodic acid-Schiff (PAS). In the process of cutting sections, some of the bronchial rings inevitably opened up at the membranous parts but this did not interfere with the measurements which followed.

The whole bronchial transection was projected on to a sheet of white drawing paper fixed to a vertical wall, at a magnification of about 10 diameters, and the whole thickness of the bronchial wall and basement membrane were traced (Fig. 1). The outer limit of the bronchial wall was taken as the junction of the outer border of a bronchial cartilage and the inner aspect of the outer perichondrium. The tracing was started at a point

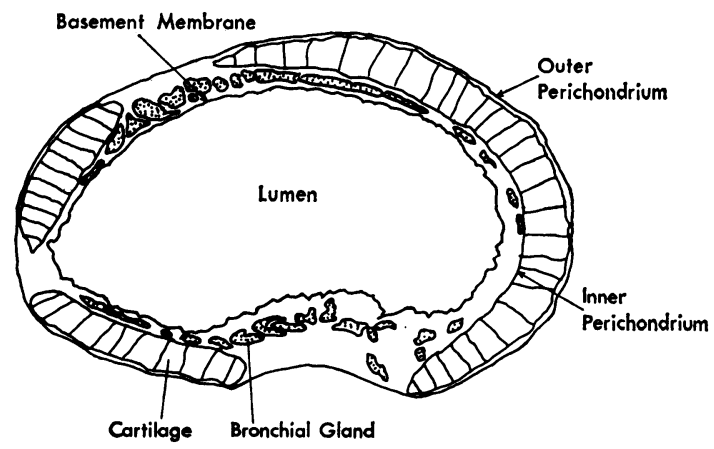

FIG. 1. Tracing of bronchial transection. where there was a cartilage plate and was then carried along the inner aspect of the outer perichondrium, through parts where there were $\frac{\bar{\sigma}}{\bar{D}}$ no cartilages, and the tracing was continued $\underset{\Phi}{\vec{D}}$ through the membranous posterior wall and along $\stackrel{\Omega}{\circ}$ the wall at its junction with the loose areola os tissue which was thus excluded from the wall $\overrightarrow{0}$ thickness. All the glands were outlined on the paper and so also were the cartilage plates. Each $\vec{\omega}$ tracing of the bronchial transection with its glands and cartilages was photocopied on to a $x$ $3 \mathrm{M}$ brand transparency film dry photo automatic, $\mathcal{O}^{\prime}$ and the transparency film copy was used in all the measurements.

THE METHOD The radial intercepts measurer is shown in Figure 2.

A systematic sampling, that is, sampling at equal sectoral distances, of the glands and the $\stackrel{\Phi}{\square}$ bronchial wall for measurement was carried out radially; hence the name of the method.

The measurer is constructed of a $300 \mathrm{~mm} \vec{\varphi}$ Perspex ruler riveted at one end to the centre or of a large circle drawn on a Perspex sheet $375 \times 375 \mathrm{~mm}$. The circumference of the circle was divided into $5^{\circ}$ segments so that there were 72 sectors numbered 1 to 72 . Seventy-two measurements could be carried out, but inter- $\Phi$ mediate $10^{\circ}$ intervals for 36 measurements were also included.

\section{MEASUREMENTS BY RADIAL INTERCEPTS MEASURER}

The bronchial tracing on the transparency film was placed on a table and the radial intercepts $\stackrel{\otimes}{x}$ measurer was placed on it so that the centre of the circle was within the lumen of the bronchial transection. The centre of the circle could be 0 made roughly to coincide with the visually estimated geometric centre of the bronchial lumen, 을 but this was not essential, and neither was it $D$ essential for the bronchial wall to be a complete ring since the few transections that opened up N during processing were equally satisfactorily measured. The weight of the grid upon the trans- O parency film ensured that there was no displace- $\mathbb{\omega}$ ment in the relative positions of the grid and the film. It was essential not to allow relative dis- 0 placement in positions before all the measurements had been made.

The riveted ruler was then rotated round the circle along each of the 72 radii in turn, starting from number 1 . The thickness of the wall, that is, the intercept between the basement membrane 


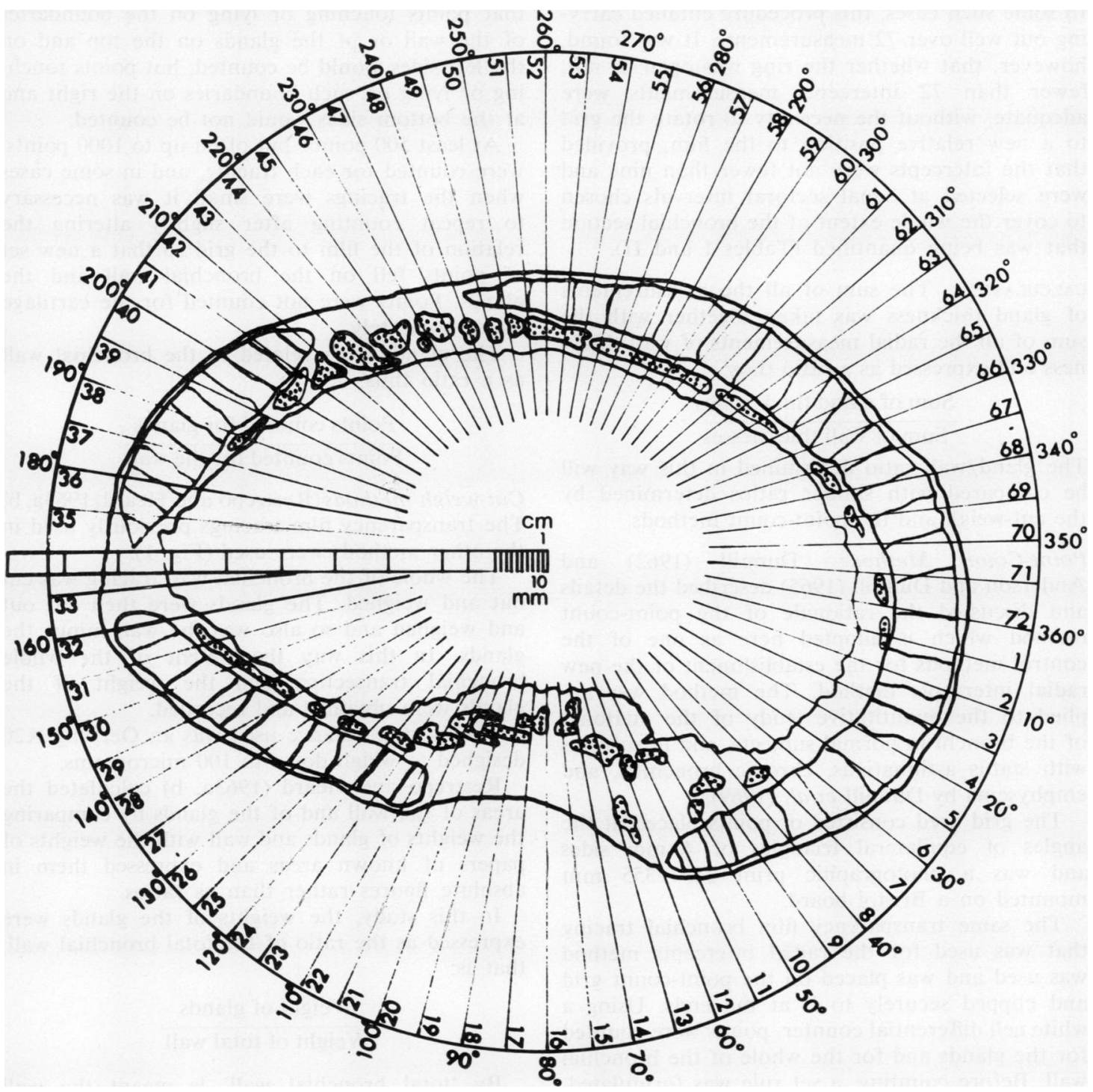

FIG. 2. The radial intercepts measurer.

and the outer boundary of the wall as traced, was read off from the ruler. The thicknesses of all the glands, that is, the intercepts made by all the gland tracings along each radius, were read off at the same time and recorded. In this systematic statistical sampling zero values for glands, that is, 'no glands' were recorded since they now had significant zero values, and the corresponding wall thicknesses were measured and included in the calculations.
Where the bronchial transections were complete rings, 72 operations were carried out, but where the transections had opened up, all the radial intercepts on the intact portions of the tracing were read and recorded and then the whole of the radial measurer was slightly rotated over the film so that a new set of intercepts on the tracing could be measured. It was essential to measure all the intercepts in a particular position of the grid before rotating it to the new position. 
In some such cases, this procedure entailed carrying out well over 72 measurements. It was found, however, that whether the ring was open or not, fewer than 72 intercepts measurements were adequate, without the necessity to rotate the grid to a new relative position to the film, provided that the intercepts were not fewer than nine and were selected at equal sectoral intervals chosen to cover the whole extent of the bronchial section that was being quantified (Tables I and II).

Calculation The sum of all the measurements of gland thickness was taken together with the sum of all the radial measurements of wall thickness and expressed as a ratio thus:

\section{Sum of gland thicknesses}

Sum of wall thicknesses

The gland/wall ratio determined in this way will be compared with similar ratios determined by the cut-weigh and the point-count methods.

Point-Count Methods Dunnill (1962) and Anderson and Dunnill (1965) described the details and discussed the rationale of the point-count method which is adopted here as one of the control methods for the establishment of the new radial intercepts method. The method was applied to the quantitative study of the anatomy of the bronchi in normal subjects, and in subjects with status asthmaticus, chronic bronchitis, and emphysema by Dunnill et al. (1969).

The grid used consisted of points placed at the angles of equilateral triangles of $4 \mathrm{~mm}$ sides and was a photographic print $355 \times 355 \mathrm{~mm}$ mounted on a Bristol board.

The same transparency film bronchial tracing that was used for the radial intercepts method was used and was placed on the point-count grid and clipped securely to it at the ends. Using a white cell differential counter, points were counted for the glands and for the whole of the bronchial wall. Before counting, a set rule was formulated, that points touching or lying on the boundaries? of the wall or of the glands on the top and on the left sides would be counted, but points touch $\overline{\text { n }}$ ing or lying on such boundaries on the right andp at the bottom sides would not be counted.

At least 500 points, but of ten up to 1000 points, were counted for each tracing, and in some caseș when the tracings were small it was necessary to repeat counting after slightly altering the relation of the film to the grid so that a new se of points fell on the bronchial wall and the glands. Points were not counted for the cartilage plates separately.

The glands were related to the bronchial walpo as a ratio thus:

\section{Points counted for glands \\ Points counted for the wall}

Cut-weigh methods (Restrepo and Heard, 1963a, b The transparency film tracings previously used in@ the other methods were used (Fig. 1).

The whole of the bronchial wall tracing was cut out and weighed. The glands were then cut out and weighed and so also was the wall minus the glands. In this way the weight of the wholes bronchial transection and the weight of the glands were obtained and recorded.

The electric balance used was an Oertling R2赵 designed to weigh down to 100 micrograms.

Restrepo and Heard (1963a, b) calculated the areas of the wall and of the glands by comparing the weights of glands and wall with the weights of papers of known areas and expressed them in absolute figures rather than as ratios.

In this study, the weights of the glands were expressed as the ratio of the total bronchial wall that is:

\section{Weight of glands \\ Weight of total wall}

By 'total bronchial wall' is meant the wa

T A B L E I

VARIATION IN GLAND/WALL RATIO WITH FREQUENCY AND NUMBER OF RADIAL INTERCEPTS MEASUREMENTS

\begin{tabular}{|c|c|c|c|c|c|c|}
\hline \multirow[b]{2}{*}{ Case } & \multicolumn{6}{|c|}{ No. of Measurements } \\
\hline & $\begin{array}{c}72 \\
\text { at } 5^{\circ} \text { apart } \\
\end{array}$ & at $10^{\circ}$ apart & $\begin{array}{c}24 \\
\text { at } 15^{\circ} \text { apart }\end{array}$ & $\begin{array}{c}18 \\
\text { at } 20^{\circ} \text { apart }\end{array}$ & at $30^{\circ}$ apart & at $40^{\circ}$ apart \\
\hline $\begin{array}{r}1 \\
2 \\
3 \\
4 \\
5 \\
6 \\
7 \\
8 \\
9 \\
10\end{array}$ & $\begin{array}{l}0.085 \\
0.075 \\
0.108 \\
0.093 \\
0.039 \\
0.084 \\
0.047 \\
0.128 \\
0.057 \\
0.087\end{array}$ & $\begin{array}{l}0.086 \\
0.072 \\
0.099 \\
0.076 \\
0.045 \\
0.091 \\
0.056 \\
0.136 \\
0.060 \\
0.086\end{array}$ & $\begin{array}{l}0.085 \\
0.072 \\
0.131 \\
0.126 \\
0.050 \\
0.092 \\
0.055 \\
0.125 \\
0.033 \\
0.086\end{array}$ & $\begin{array}{l}0.089 \\
0.055 \\
0.101 \\
0.078 \\
0.055 \\
0.091 \\
0.055 \\
0.137 \\
0.033 \\
0.061\end{array}$ & $\begin{array}{l}0.086 \\
0.062 \\
0.130 \\
0.076 \\
0.067 \\
0.093 \\
0.097 \\
0.134 \\
0.042 \\
0.058\end{array}$ & $\begin{array}{l}0.089 \\
0.061 \\
0.114 \\
0.098 \\
0.042 \\
0.097 \\
0.065 \\
0.145 \\
0.040 \\
0.045\end{array}$ \\
\hline
\end{tabular}


T A B L E I I

STATISTICAL EVALUATION OF VARIATION IN GLAND/WALL RATIO WITH FREQUENCY AND NUMBER OF RADIAL INTERCEPTS MEASUREMENTS

72 measurements at $5^{\circ} v 36$ measurements at $10^{\circ} ; t=0.15 \mathrm{NS}$

72 measurements at $5^{\circ} v 24$ measurements at $15^{\circ} ; t=1.06 \mathrm{NS}$

72 measurements at $5^{\circ} v 15$ measurements at $20^{\circ} ; t=0.97 \mathrm{NS}$

72 measurements at $5^{\circ} v 12$ measurements at $30^{\circ} ; t=0.56 \mathrm{NS}$

72 measurements at $5^{\circ} v 9$ measurements at $40^{\circ} ; t=0.07 \mathrm{NS}$

$t=$ correlation coefficient; $\mathrm{NS}=$ no significant difference.

tracing from which the glands had not been cut out.

\section{RESULTS}

Detailed individual results for the three different methods are available on request to the author. The results for the single case in which planimetry was carried out are shown in Table III.

\section{T A B L E I I I}

COMPARISON OF GLAND/WALL RATIO (G/W) BY PLANIMETRY WITH G/W BY OTHER METHODS (ONE CASE ONLY)

\begin{tabular}{l|l}
\hline \multicolumn{1}{c|}{ Methods } & G/W \\
\hline Point-counting (Dunnill, 1962) & $0 \cdot 1113$ \\
Cut-and-weigh (Restrepo and Heard, 1963) & $0 \cdot 1077$ \\
Radial intercepts (this paper) & $0 \cdot 1114$ \\
Planimetry & $0 \cdot 0895$ \\
\hline
\end{tabular}

The results obtained by the various methods have been correlated statistically (Table IV) and, as can be seen, the radial intercepts, the cutweigh, and the point-count methods are highly correlated with each other $(\mathrm{P}<0.001)$. In the one case in which planimetric area measurements were carried out, there was good correlation between planimetry, radial intercepts, point-count, and cut-weigh methods (Table III).

\section{DISCUSSION}

The imperceptible blending of the peribronchial connective tissue with the outer perichondrium makes it difficult to decide precisely the line of cleavage between the outer perichondrium and the areola connective tissue. However, a close study of the outer perichondrium will show that in a well-processed bronchial transection free from artefact, there is a definable, even though potential line of cleavage between the cartilage and the inner aspect of the outer perichondrium. This line can be projected easily along the bronchial wall, including the membranous part, to define a reproducible bronchial wall boundary. The advantage of doing this is that in most cases all the bronchial glands are included in the wall so demarcated. This principle has been employed in this study, and it was easy to trace the wall in this way when projected on a screen or when viewed with the camera lucida.

Bedrossian et al. (1971) thought that the sources of error in Reid's original method were the variation in gland sizes and the presence of glands between and external to cartilage plates which the method did not include in the measurements used to calculate the Reid Index. The radial intercepts method is designed to overcome this criticism as it takes account of the variation in gland sizes and of all the glands present in the bronchial wall.

Using standard planimetric measurements as controls, Bedrossian et al. (1971) showed that the point-count and the cut-weigh methods are the methods of choice for the accurate determination of the relative proportions of bronchial wall components.

The high correlation which the radial intercepts method shows with the cut-weigh and the pointcount methods is proof of its reliability and accuracy.

The radial intercepts method is not only reliable but it is also convenient to use and it may be employed, where applicable, to quantify the components of biological materials other than those of the bronchial wall.

The radial measurer can be fixed to a wall or to a vertical stand and the bronchial transection projected on to it. For ease in measurement and

T A B L. E I V

DEGREE OF CORRELATION BETWEEN THE DIFFERENT METHODS FOR DETERMINATION OF GLAND/WALL RATIO (G/W)

\begin{tabular}{|c|c|c|}
\hline Method & Mean $\mathbf{G} / \mathbf{W}$ & Standard Deviation \\
\hline $\begin{array}{l}\text { Point-counting } \\
\text { Cut-and-weigh } \\
\text { Radial intercepts }\end{array}$ & $\begin{array}{l}0.0920 \\
0.0922 \\
0.0921\end{array}$ & $\begin{array}{l}0 \cdot 0447 \\
0 \cdot 0460 \\
0 \cdot 0439\end{array}$ \\
\hline Methods Compared & $\mathbf{r}$ & $\mathbf{P}$ \\
\hline $\begin{array}{l}\text { Point-counting } v \text { cut-and-weigh } \\
\text { Point-counting } v \text { radial intercepts } \\
\text { Cut-and-weigh } v \text { radial intercepts }\end{array}$ & $\begin{array}{l}0 \cdot 9567 \\
0 \cdot 9492 \\
0 \cdot 9396\end{array}$ & $\begin{array}{l}<0.001 \\
<0.001 \\
<0.001\end{array}$ \\
\hline
\end{tabular}


to reduce doubts about the outer boundary of the wall during measurement, only the outer bronchial wall need first be traced out, as described earlier, and then with the rotating ruler riveted to the dial, the thickness of the glands and the corresponding wall thicknesses are read off along the radial intercepts. The method is also convenient to use with the camera lucida and it can be adapted for microscopical measurements by incorporating the radial measurer as an eyepiece graticle. Since not every laboratory, particularly in the developing countries, is equipped with an electric balance, this method commends itself to a wide use and it is less tedious than cutting the glands out of paper or pointcounting them.

This work was completed while I was at the Department of Pathology, the Midland Centre for Neurosurgety and Neurology (MCNN), Smethwick, Warley, England. It is with pleasure I acknowledge the kindness of Drs. G. W. Pearce and M. V. Salmon, and of the members of their technical staff. The radial intercepts measurer was constructed by $\mathrm{Mr}$. Derek Hayward, MCNN, and I had useful hints about the methodology of statistical sampling from Dr. David Ellis. The statistical analyses were carried out by Mrs. J. M. Thompson and Miss Mary Wall, Statistics Department, Birmingham Regional Hospital Board, Birmingham, England. Professor D. B. Brewer of the University of Birmingham showed great interest in this work and his advice is gratefully acknowledged. I acknowledge with gratitude the technical assistance I received from my wife, Mrs. Rosemary J. Alli, and from Mr. Emiola Gbela, of the Department of Pathology, ABU Hospital, Zaria, where I began this study.

\section{REFERENCES}

Anderson, J. A. and Dunnill, M. S. (1965). Observations on the estimation of the quantity of emphysema in the lungs by the point-sampling method. Thorax, 20, 462 .

Bedrossian, W. M., Anderson, A. E. Jr., ang Foraker, A. G. (1971). Comparison of methog for quantitating bronchial morphology. Thora $\$$ 26, 406.

Dunnill, M. S. (1962). Quantitative methods in the study of pulmonary pathology. Thorax, 17, 320 $\overrightarrow{0}$

Dunnill, M. S., Massarella, G. R., and Anderson. J. A. (1969). A comparison of the quantitatire anatomy of the bronchi in normal subjects, status asthmaticus, in chronic bronchitis, and emphysema. Thorax, 24, 176.

Hayes, J. A. (1969). Distribution of bronchial glang measurements in a Jamaican populatiog Thorax, 24, 619.

Reid, L. (1960). Measurement of the bronchid mucous gland layer: a diagnostic yardstick $\bar{F}$ chronic bronchitis. Thorax, 15, 132.

Restrepo, G. L. and Heard, B. E. (1963a). The si of the bronchial glands in chronic bronchitie Journal of Pathology and Bacteriology, 85, 30 and - (1963b). Mucous gland enlargemerat in chronic bronchitis: extent of enlargement in the tracheobronchial tree. Thorax, 18, 334.

Rosiwal, A. (1898). Uber geometrische Gesteinșanalysen. Ein facher Weg zur ziffermässigem Feststellung des Quantitätsverhältnisses de Mineral bestandteile gemengter Gesteine. Verf Königlich-Kaiserliches Geol. Reichsamt (Wien p. 143.

Thurlbeck, W. M. and Angus, G. E. (1963). The relationship between emphysema and chronic bronchitis as assessed morphologically. American Review of Respiratory Diseases, 87, 815. and (1964). A distribution curve for chron bronchitis. Thorax, 19, 436. and - (1967). The variation of Reid inde measurements within the major bronchial tree American Review of Respiratory Diseases, 9\$, 551 .

Requests for reprints to: Professor A. F. Alli Department of Pathology, College of Medicine University of Benin, Benin City, Nigeria. 